\title{
Effect of Aging Treatment on the Mechanical Properties of C-250 Maraging Steel by Flow Forming
}

\author{
I.K. Lee, C.P. Chou, C.M. Cheng, and I.C. Kuo
}

(Submitted 17 September 2001; in revised form 25 June 2002)

\begin{abstract}
The technique of forward flow forming has been used to produce a long, thin walled tube made of C-250 maraging steel. The forward flow forming can save raw material, increase strength, and reduce the production process time. Because the work hardening effect on solution-treated C-250 using flow forming is minimal, the flow-formed tube requires an additional heat treatment to obtain higher hardness and strength. With the direct aging treatment, low elongation values are obtained, making this treatment unsuitable for the engineering design. It was found that the $540{ }^{\circ} \mathrm{C} / 6 \mathrm{~h} / \mathrm{AC}$ over-aging treatment results in better strength and elongation values. The strengthening phase of the flow-formed $\mathrm{C}-250$ maraging steel was found to be the intermetallic compound of $\mathrm{Fe}_{3} \mathrm{Mo}$.
\end{abstract}

Keywords aging treatment, flow-forming, maraging steel C-250

\section{History}

The $18 \%$ nickel maraging steel owes its outstanding characteristics to certain specific features of the iron-nickel based alloys. The martensitic structure with a low rate of distortion can be attributed to the extra-low carbon $(<0.03 \mathrm{wt} . \%)$ content. In the solution-annealed state, after air cooling from the elevated temperatures, a body-centered cubic (bcc; $\alpha$-phase) structure is present ${ }^{[1,2,3]}$ and it can be easily shaped using conventional processes such as rolling, forging, and flow forming. ${ }^{[3]}$ To strengthen the maraging steel, a high temperature aging treatment is required. The main hardening precipitates of intermetallic compounds include $\mathrm{Ni}_{3} \mathrm{Mo}, \mathrm{Ni}_{3} \mathrm{Ti}, \mathrm{Fe}_{2} \mathrm{Mo}$, or FeTiMo. ${ }^{[2,3,4]}$

The technique of forward flow forming has been used to produce a long, thin-walled tube of C-250 maraging steel. Flow forming can produce parts nearer to net shape than forging, eliminate some initial rough machining, conserve material, increase strength, and reduce the production process time. ${ }^{[5,6]}$ Due to the minimal work hardening effect of solution-treated $\mathrm{C}-250$ by the flow-forming process, ${ }^{[1]}$ the flow-formed tube requires an additional aging treatment to obtain higher hardness and strength. ${ }^{[4]}$

\section{Materials}

The material used was C-250 maraging steel which has been double vacuum melted using vacuum induction meltingvacuum air remelting (VIM-VAR) according to AMS 6512C. ${ }^{[7]}$ The chemical composition of C-250 maraging steel was measured by scanning electron microscopy (SEM)/energy

I.K. Lee, C.P. Chou, C.M. Cheng, and I.C. Kuo, Department of Mechanical Engineering, National Chiao Tung University, Hsinchu, Taiwan, R.O.C. Contact e-mail: iklee@tpts5.seed.net.tw.
Table 1 Chemical Composition of C-250 Maraging Steel, wt.\%

\begin{tabular}{lccrr}
\hline Element & $\begin{array}{c}\text { Specifications } \\
\text { AMS 6512 C }\end{array}$ & $\begin{array}{c}\text { Used in } \\
\text { This Work }\end{array}$ & A(a) & B(a) \\
\hline $\mathrm{Al}$ & $0.05 \sim 0.15$ & 0.15 & 0.44 & 0.00 \\
$\mathrm{Mo}$ & $4.6 \sim 5.2$ & 4.9 & 12.95 & 4.63 \\
$\mathrm{Ti}$ & $0.3 \sim 0.5$ & 0.5 & 0.38 & 0.44 \\
$\mathrm{Co}$ & $7.0 \sim 8.5$ & 8.6 & 6.05 & 8.36 \\
$\mathrm{Ni}$ & $17 \sim 19$ & 17.6 & 16.74 & 16.95 \\
$\mathrm{C}$ & 0.03 & 0.003 & $\ldots$ & $\ldots$ \\
$\mathrm{Cr}$ & $<0.50$ & $\ldots$ & $\ldots$ & $\ldots$ \\
$\mathrm{Cu}$ & $<0.5$ & $\ldots$ & $\ldots$ & $\ldots$ \\
$\mathrm{Fe}$ & $\mathrm{Bal}$ & $\mathrm{Bal}$ & 63.43 & 69.62
\end{tabular}

(a) Chemical compositions of Fig. 10b

dispersive $\mathrm{x}$-ray analysis (EDX) and carbon analysis. The results are presented in Table 1. After solution treating at $815^{\circ} \mathrm{C}$ for $1 \mathrm{~h}$, the preforms were cold forward flow-formed from $8.0-1.7 \mathrm{~mm}$ by one pass. The reduction rate of thickness was $78.8 \%$.

\section{Experimental Methods}

To increase the strength after flow forming, several types of additional heat treatments were performed. The flow-formed tubes were heat treated in three aging conditions: under-aged $\left(370{ }^{\circ} \mathrm{C} / 10 \mathrm{~h} / \mathrm{AC}, 480{ }^{\circ} \mathrm{C} / 1 \mathrm{~h} / \mathrm{AC}\right)$; aged $\left(480{ }^{\circ} \mathrm{C} / 3 \mathrm{~h} / \mathrm{AC}, 480\right.$ $\left.{ }^{\circ} \mathrm{C} / 6 \mathrm{~h} / \mathrm{AC}\right)$; and over-aged $\left(540{ }^{\circ} \mathrm{C} / 6 \mathrm{~h} / \mathrm{AC}, 580{ }^{\circ} \mathrm{C} / 6 \mathrm{~h} / \mathrm{AC}\right)$, as shown in Table 2 . The flow chart of the experiments schedule is shown in Fig. 1.

The microstructures of flow-formed and aged samples of the preform were observed. The positions for microstructural analysis were in the cross section of the flow-formed tube wall. Specimens were polished to $0.005 \mu \mathrm{m}$, etched with $30 \mathrm{ml} \mathrm{HCl}$ $+10 \mathrm{ml} \mathrm{HNO}_{3}+\mathrm{CuCl}_{2}$, and examined using an optical microscope. Hardness was measured on the Vickers hardness scale with $300 \mathrm{~g} / 15 \mathrm{~s}$. The scale was then auto-transformed to a Rockwell C scale (HRC). The microstructures of the flow- 


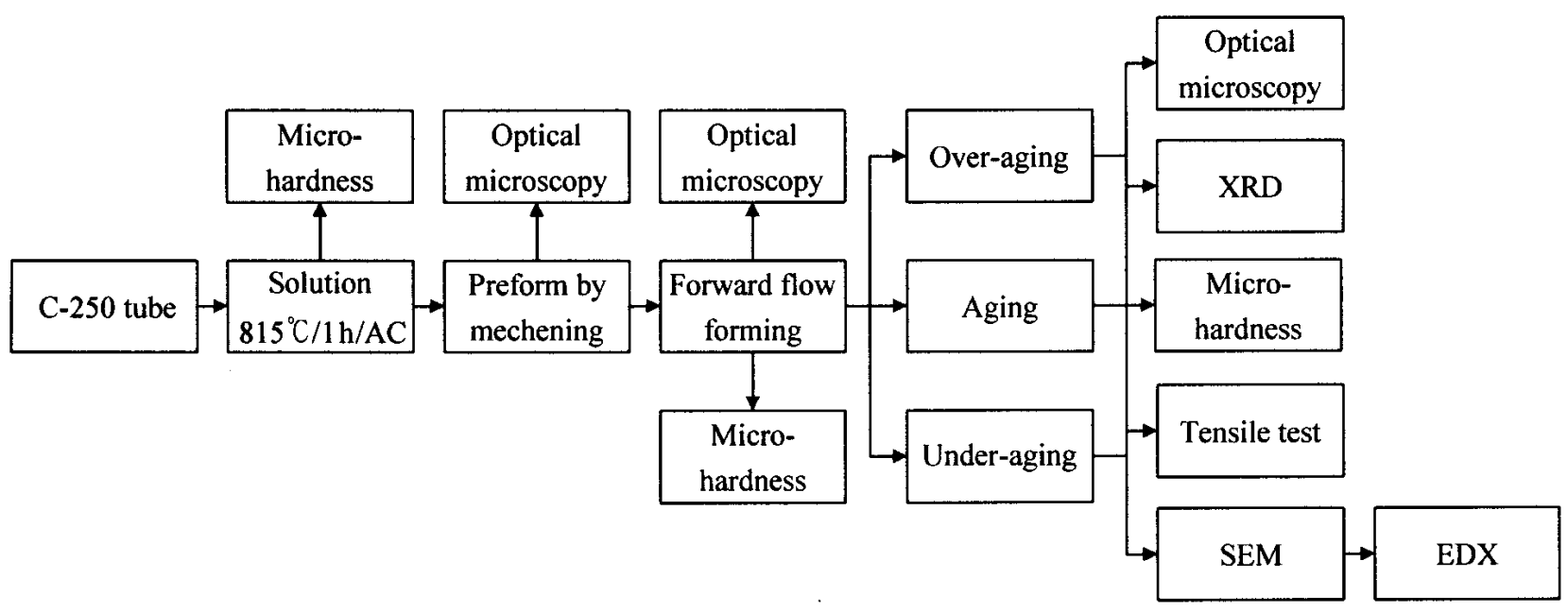

Fig. 1 The flow chart of experiments of C-250 maraging steel

Table 2 Mechanical Properties of Aging Treated Flow Formed C-250 Maraging Steel in Different Aging Treatments

\begin{tabular}{|c|c|c|c|c|}
\hline Sample No. & Heat Treating Process & YS, MPa, (0.2\% Offset) & UTS, MPa & Elongation, \% \\
\hline $370-1$ & Solution $\rightarrow$ forming & 1018.0 & 1145.0 & 5.1 \\
\hline $370-2$ & Solution $\rightarrow$ forming $\rightarrow$ aging $370 / 10 \mathrm{~h}$ & 1529.0 & 1565.0 & 1.9 \\
\hline $370-3$ & Solution $\rightarrow$ forming $\rightarrow$ aging $480 / 1 \mathrm{~h}$ & 1763.0 & 1795.0 & 1.1 \\
\hline $370-4$ & Solution $\rightarrow$ forming $\rightarrow$ aging $480 / 3 \mathrm{~h}$ & 1956.0 & 1977.0 & 1.6 \\
\hline $370-5$ & Solution $\rightarrow$ forming $\rightarrow$ aging $480 / 6 \mathrm{~h}$ & 1930.0 & 1954.0 & 1.6 \\
\hline $370-6$ & Solution $\rightarrow$ forming $\rightarrow$ aging $540 / 6 \mathrm{~h}$ & 1800.0 & 1884.0 & 3.6 \\
\hline $370-7$ & Solution $\rightarrow$ forming $\rightarrow$ aging $580 / 6 \mathrm{~h}$ & 1528.0 & 1620.0 & 5.2 \\
\hline
\end{tabular}

formed samples were identified by $\mathrm{x}$-ray diffraction (XRD) using a Siemens Diffractometer D5000 (Germany), with a Cu$\mathrm{K}_{\alpha}$ beam source $(\lambda=1.5418 \AA)$. The scanning angle range covered from $40-90^{\circ}$ and the scanning speed was $1 \%$ min.

The tensile specimens were made following guidelines from ASTM standard E370 by milling along the axis direction of the tube (Fig. 2). The gage length was $50.8 \mathrm{~mm}$. The strain rate was $0.2 \mathrm{~mm} / \mathrm{min}$ before yield strength (YS) and $2 \mathrm{~mm} / \mathrm{min}$ after YS. Six specimens were tested for each condition. Fractographic observations of tensile-tested samples in as-formed and aged condition were made in a $20 \mathrm{kV}$ SEM to determine the failure modes. EDX of fragmented particles was used to analyze the chemical composition.

\section{Discussion and Results}

The result of chemical composition analysis is shown in Table 2. All elements are within the range of standard C-250 (AMS 6512C) except cobalt (Co), which is higher than the standard value. ${ }^{[7]}$

Figure 3 shows the optical micrographs of C-250 maraging steel before and after flow forming. The C-250 preform treated by solution-annealing treatment is shown in Fig. 3(a). The fine equiaxed crystal was clearly seen in the matrix phase. No standard lath martensite structure was seen in the microstructure. ${ }^{[3]}$ Figure 3(b) indicates that $\alpha$-phase was precipitated in the matrix and no deformed grains were observed.

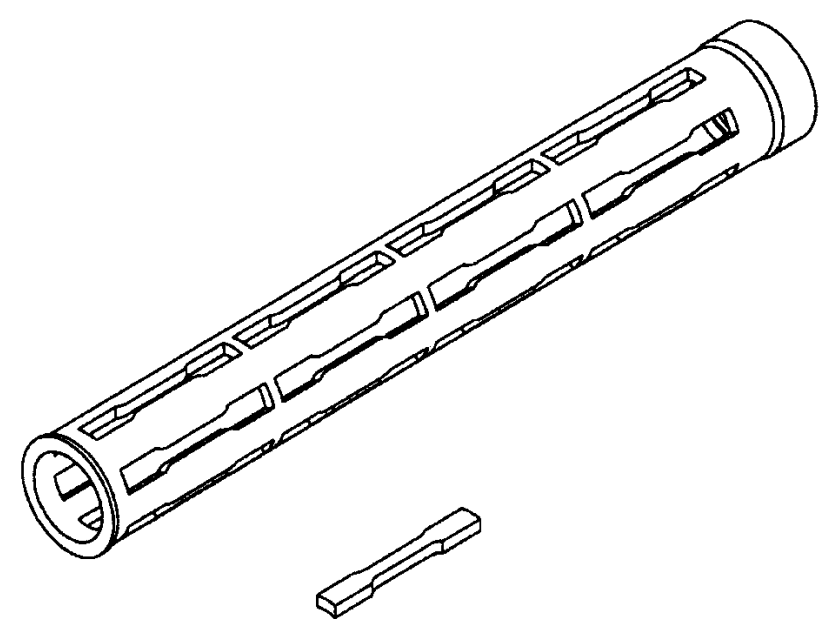

(a)

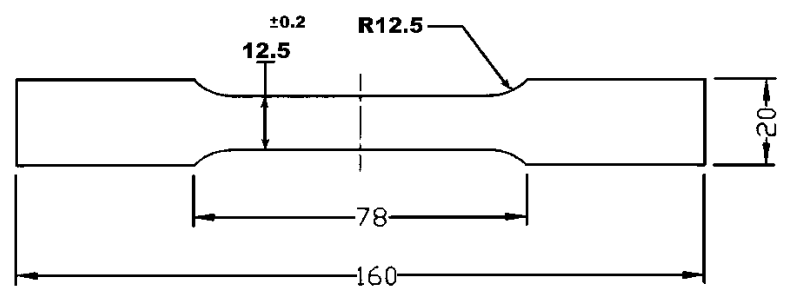

(b)

Fig. 2 Dimensions of tensile specimen 

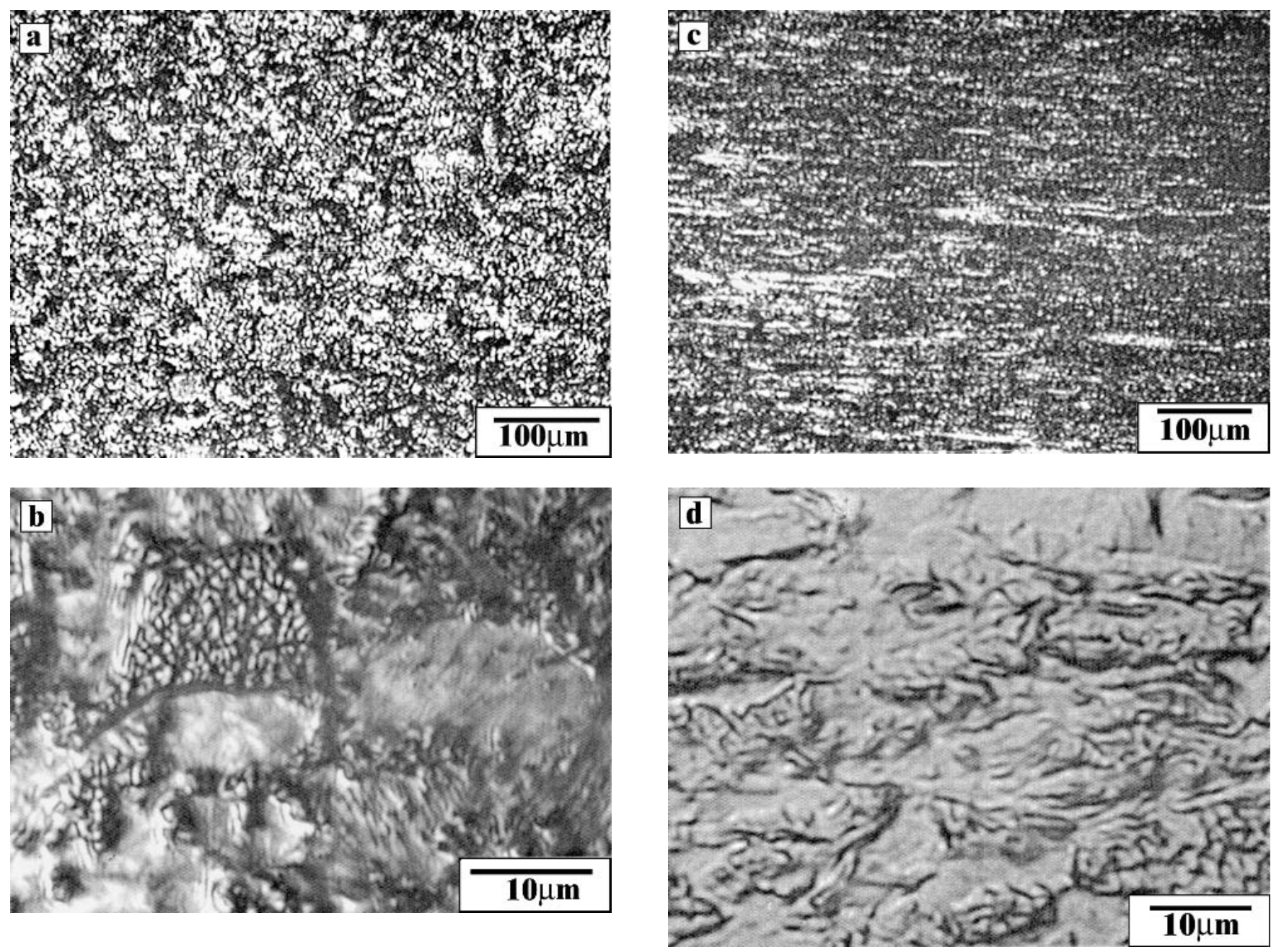

Fig. 3 Optical micrograph of C-250 maraging steel: (a) and (b) preform; (c) and (d) after flow forming

The microstructure of flow-formed $(8.0 \mathrm{t} \rightarrow 1.7 \mathrm{t}) \mathrm{C}-250$ maraging steel is shown in Fig. 3(c). The average microhardness of the outside part is $35.1 \mathrm{HRC}$ after work-hardening, an increase of 4.9 HRC scale. The microhardness of the inner part of the formed tube is $32 \mathrm{HRC}$. This difference in hardness indicates that the effect of cold working for forward flow forming is not uniform, as shown in Fig. 4. The flow-formed tube was driven by forming stress in both the axial and radial directions. Under the stress of forming, the microstructure was distorted and an extended grain shape is observed (Fig. 3d).

The microstructures of the flow-formed tube after two different aging treatments are shown in Fig. 5. The hardness was increased to 51.6 HRC after a single aging treatment and 52.1 HRC after a double aging treatment. These values were about the same as the standard values of the testing material. After the aging treatment, the hardness of flow-formed C-250 maraging steel was increased to almost twice that of the as-formed steel; however, the microstructure had no obvious change as shown in Fig. 3(c) and 5.

The results of tensile tests of the flow-formed tube of C-250 maraging steel in the as-formed, under-aged, aged, and overaged conditions are presented in Table 2 .
According to AMS specification $6520 \mathrm{C}^{[8]}$ of C-250 maraging steel, the standard values are as follows: yield strength (YS) - $1689 \mathrm{MPa}$; ultimate tensile strength (UTS) - 1758 $\mathrm{MPa}$; elongation rate (Gage $50.8 \mathrm{~mm})-2.5 \%$. The YS and UTS of specimen $370-4$ are $15.8 \%$ and $12.5 \%$ higher than the standard values, respectively, but the elongation is lower than that of the standard value. With the standard aging treatment condition on the formed tube, the combined effect of workhardening and precipitation-hardening should enhance the tensile strength.

According to Floreen's suggestion, ${ }^{[3]}$ the over-aging treatment can be used to reduce the strength and increase the elongation rate in two ways: (1) with the standard treatment temperature of $480{ }^{\circ} \mathrm{C}$, the aging time should be extended to over $100 \mathrm{~h}$; and (2) with a higher aging treatment temperature.

After flow forming, the mechanical properties of C-250 are dependent on the aging time (Fig. 6). In the $480{ }^{\circ} \mathrm{C} / 1 \mathrm{~h} / \mathrm{AC}$ condition, the tensile strength of the formed tube cannot reach the maximum value from aging precipitation, but the elongation drops to the lowest as indicated in Fig. 6. The newly precipitated intermetallic compounds may prevent the future dislocation slip; therefore, the tensile strength is increased and 


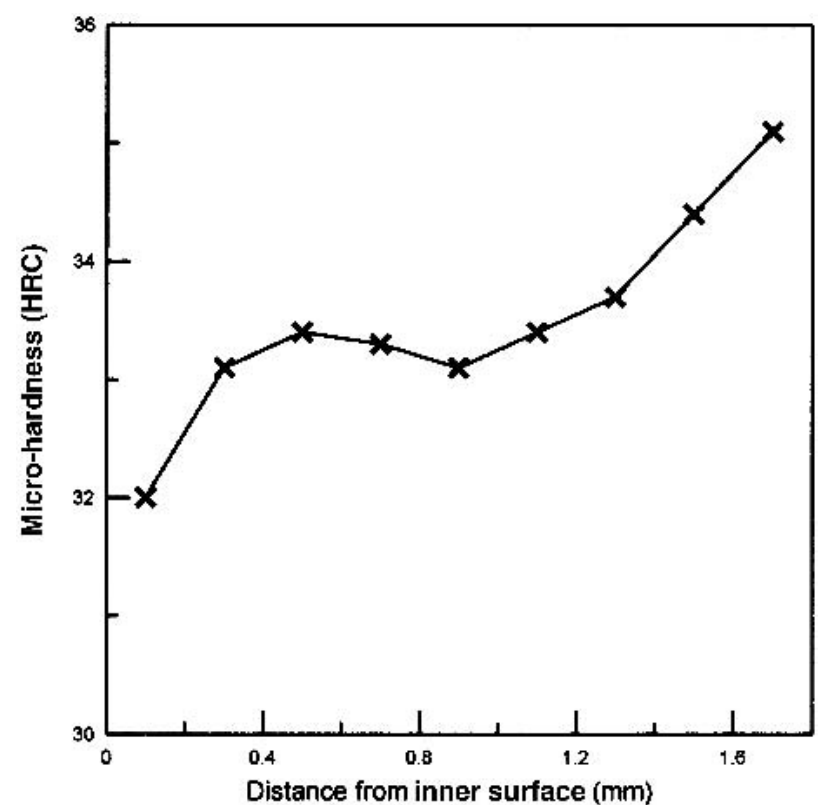

Fig. 4 The hardness distribution in the cross section of wall by flow-formed tube of C-250 maraging steel
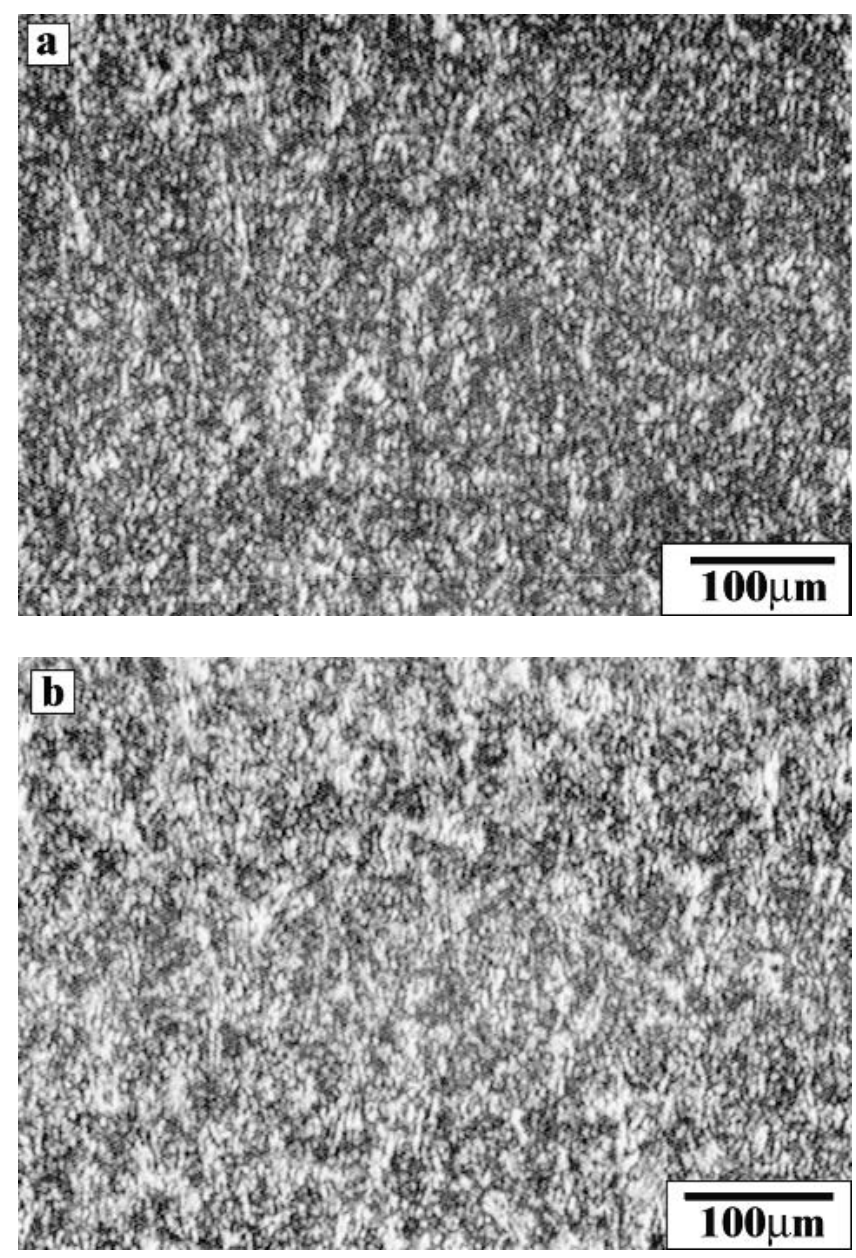

Fig. 5 Optical micrographs of flow-formed C-250 maraging steel after (a) $480{ }^{\circ} \mathrm{C} / 6 \mathrm{~h} / \mathrm{AC}$; and (b) $480{ }^{\circ} \mathrm{C} / 6 \mathrm{~h} / \mathrm{AC}+480{ }^{\circ} \mathrm{C} / 6 \mathrm{~h} / \mathrm{AC}$

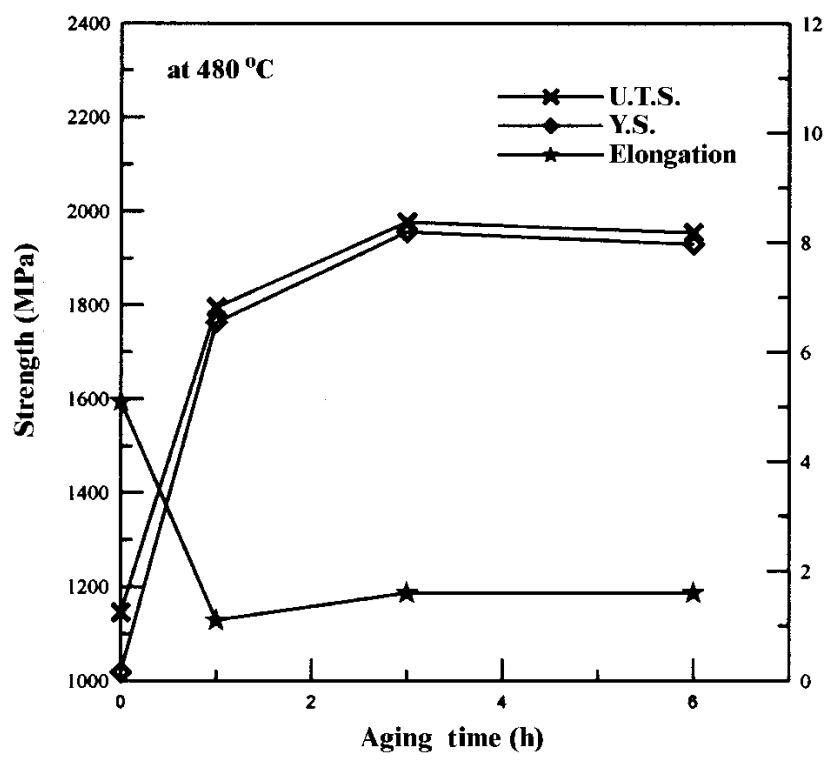

Fig. 6 Mechanical properties versus aging time of C-250 flowformed maraging steel

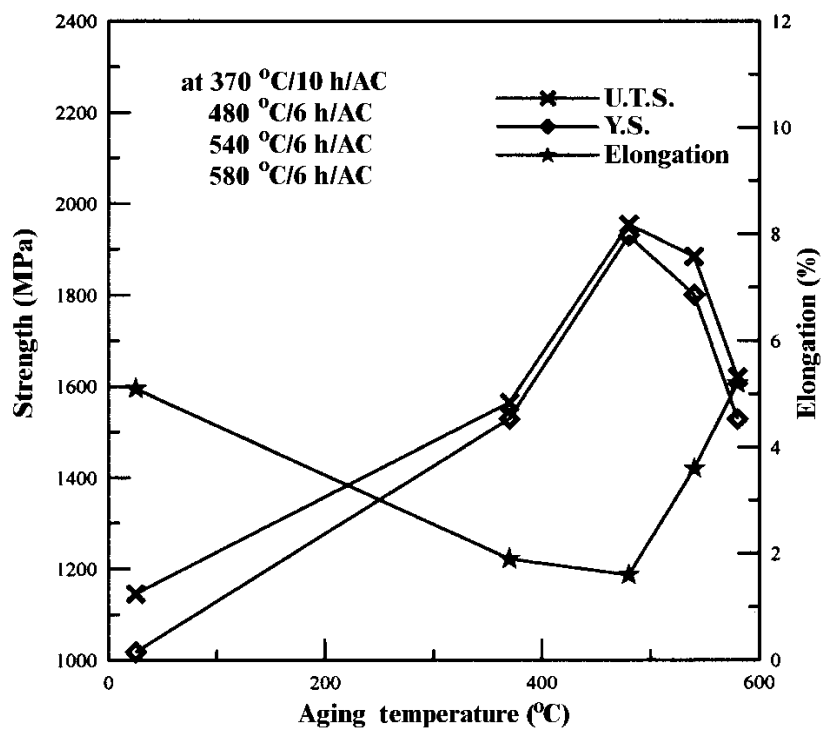

Fig. 7 Mechanical properties versus aging temperature of C-250 flow-formed maraging steel

the elongation rate is decreased. As the standard aging time was extended to $6 \mathrm{~h}(370-5)$, the value of tensile strength was similar to that of $370-4$. This result indicates that the aging temperature $480{ }^{\circ} \mathrm{C}$ can produce stable results. This is consistent with the results of other reports. ${ }^{[3]}$

Figure 7 shows the effect of aging temperature on the mechanical properties of flow-formed C-250 maraging steel. It was shown that the tensile strength increased smoothly when the aging temperature was under $370{ }^{\circ} \mathrm{C}$. The maximum value of the tensile strength can be achieved as the temperature was increased to $480{ }^{\circ} \mathrm{C}$. However, the elongation rate was reduced to the lowest value. When the aging temperature was increased, the strength dropped. At the higher temperature for $6 \mathrm{~h}$, the 


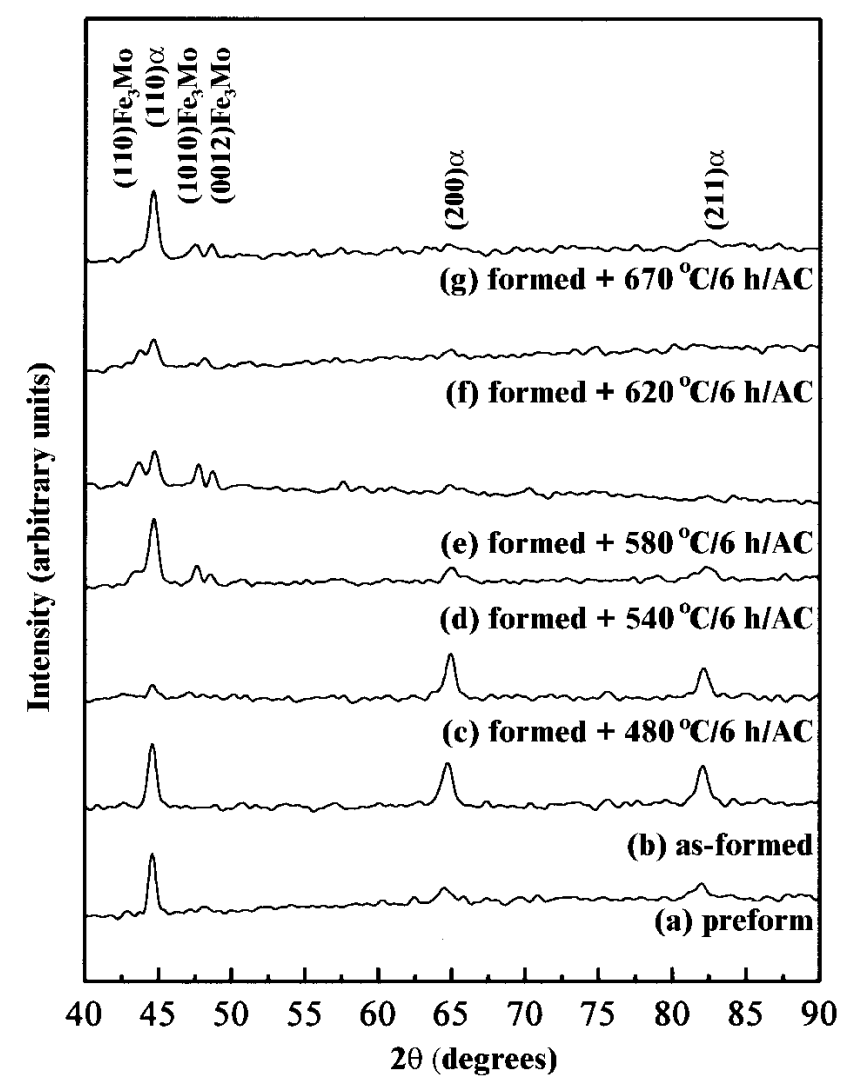

Fig. 8 X-ray diffractogram of C-250 maraging steel. (a) preform, (b) as-formed, and flow formed + , (c) $480{ }^{\circ} \mathrm{C} / 6 \mathrm{~h}$, (d) $540{ }^{\circ} \mathrm{C} / 6 \mathrm{~h}$, (e) 580 ${ }^{\circ} \mathrm{C} / 6 \mathrm{~h}$, (f) $620{ }^{\circ} \mathrm{C} / 6 \mathrm{~h},(\mathrm{~g}) 670{ }^{\circ} \mathrm{C} / 6 \mathrm{~h}$

strength obtained reached the value of the over-aging treatment. The high temperature (HT) enhanced the diffusion rate, the aged precipitates were clustered, and grain coarsening occurred. Also, at HT the solid solubility of alloy elements was higher in the matrix-phase and the amount of aged precipitates was decreased. As the aging temperature was increased to over $500{ }^{\circ} \mathrm{C}$, the strength was further decreased and the elongation increased. This heat treatment can cause the martensite to transform into softer austenite and is called "austenite reversion." ${ }^{[3,9]}$ With much higher temperature aging treatments, the behavior of the reversion became more complete. Figure 7 shows that the elongation rate increased from $1.6 \%$ at $480{ }^{\circ} \mathrm{C}$ to $3.6 \%$ at $540{ }^{\circ} \mathrm{C}$ and up to $5.2 \%$ at $580{ }^{\circ} \mathrm{C}$.

The XRD spectra obtained from the preform, as-formed, and as-aged (from $480-670{ }^{\circ} \mathrm{C}$ ) samples are shown in Fig. 8. It has been observed that the preform of C-250 maraging steel usually transforms into bcc martensite at room temperature after air-cooling from $815^{\circ} \mathrm{C}$ (Fig. 8a). The relative peak intensities of the preform sample corresponded to the values expected of a homogeneous and equiaxed material (Fig. 3b). The maximum intensity in the preform condition is observed at the $(110)_{\alpha}$ peak position. In the as-formed state, the maximum intensity is also at the $(110)_{\alpha}$ peak position. But the increase in the $(200)_{\alpha}$ and $(211)_{\alpha}$ peak intensities was also observed in the as-formed state. The changes observed in the relative peak intensities are undoubtedly due to the incorporated texture. ${ }^{[4]}$ These results are similar to the results obtained by Ali et al. ${ }^{[10]}$

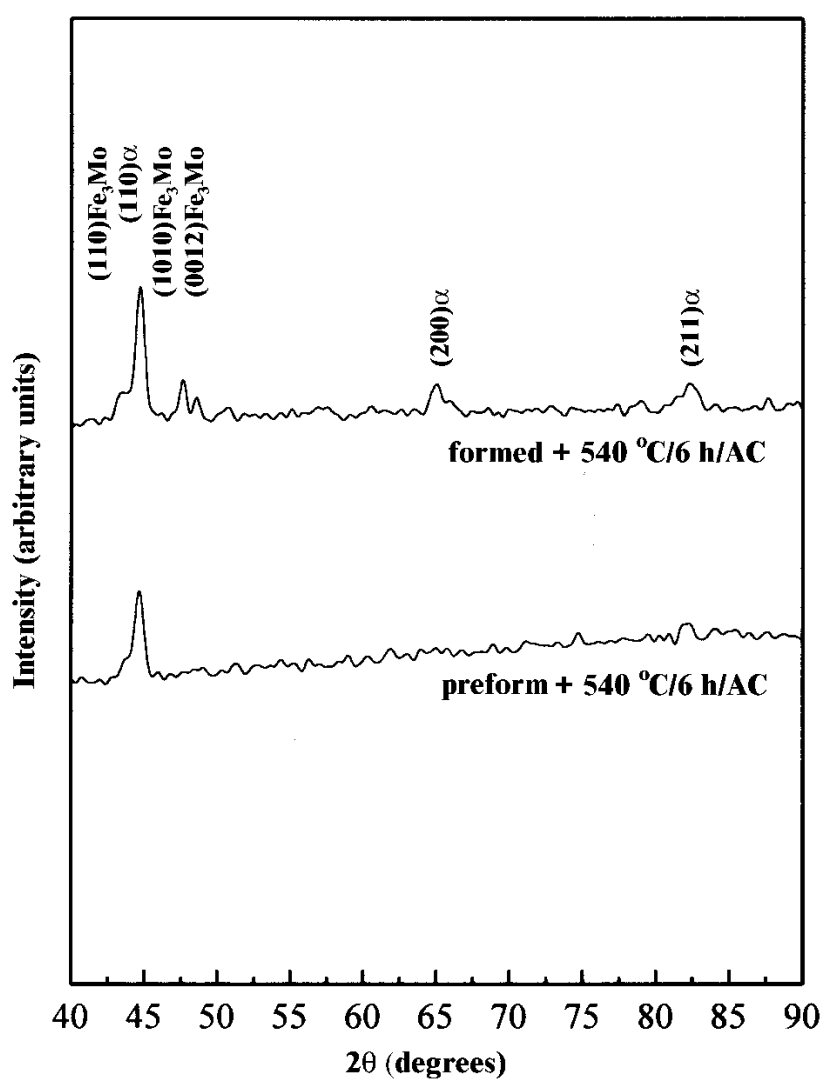

Fig. 9 X-ray diffractogram of C-250 maraging steel: preform +540 ${ }^{\circ} \mathrm{C} / 6 \mathrm{~h}$ and formed $540{ }^{\circ} \mathrm{C} / 6 \mathrm{~h}$

They found that the relative intensities of the x-ray spectra start to change when reduction ratios were above 50 for flowformed $18 \mathrm{Ni} 350$ grade maraging steel.

To study the effects of aging on the texture, as-formed samples were aged at various temperatures. The XRD spectra obtained from formed plus aging specimens are also shown in Fig. 8. The (110), (1010), and (0012) peaks of $\mathrm{Fe}_{3} \mathrm{Mo}$ phase were first detected in samples aged at $540{ }^{\circ} \mathrm{C}$ for $6 \mathrm{~h}$ (Fig. 8d). The relative (110) $\mathrm{Fe}_{3} \mathrm{Mo}$ peak intensity of the aged samples increases as the aging temperature increases from $540-620^{\circ} \mathrm{C}$. However, the strengthening phases of maraging steel are formed by heterogenous precipitation, and these phases have been identified as intermetallic compounds of the $\mathrm{Ni}_{3}(\mathrm{Ti}, \mathrm{Mo})$ and $\mathrm{Fe}_{2}$ Mo types. ${ }^{[11]}$ A general formula of the type $(\mathrm{Ni}, \mathrm{Fe}$, $\mathrm{Co})_{3}(\mathrm{Ti}, \mathrm{Mo})$ has been assigned to these precipitates. The concentration of Mo and $\mathrm{Ti}$ in the precipitates are dictated by the relative amounts of these elements present in the alloy. ${ }^{[1]} \mathrm{It}$ has been shown ${ }^{[11,12]}$ that the $\mathrm{Ni}$ and $\mathrm{Ti}$ atom in the $\mathrm{Ni}_{3} \mathrm{Ti}$ unit cell can be replaced by the $\mathrm{Fe}$ and Mo atom, respectively. The $\mathrm{A}_{3} \mathrm{~B}$ precipitates with a hexagonal close-packed (cph) structure are favored due to the better lattice fit with the bcc martensite. ${ }^{[11]}$ Flow forming can enhance the precipitation of intermetallic $\mathrm{Fe}_{3}$ Mo phase as shown in Fig. 9.

Figure 10 shows typical SEM fractographs of tensile-tested sample in as-formed condition. Examination of the fracture surface indicates the presence of nonuniform dimples (Fig. 10a). The larger dimples could be associated with the initiation 

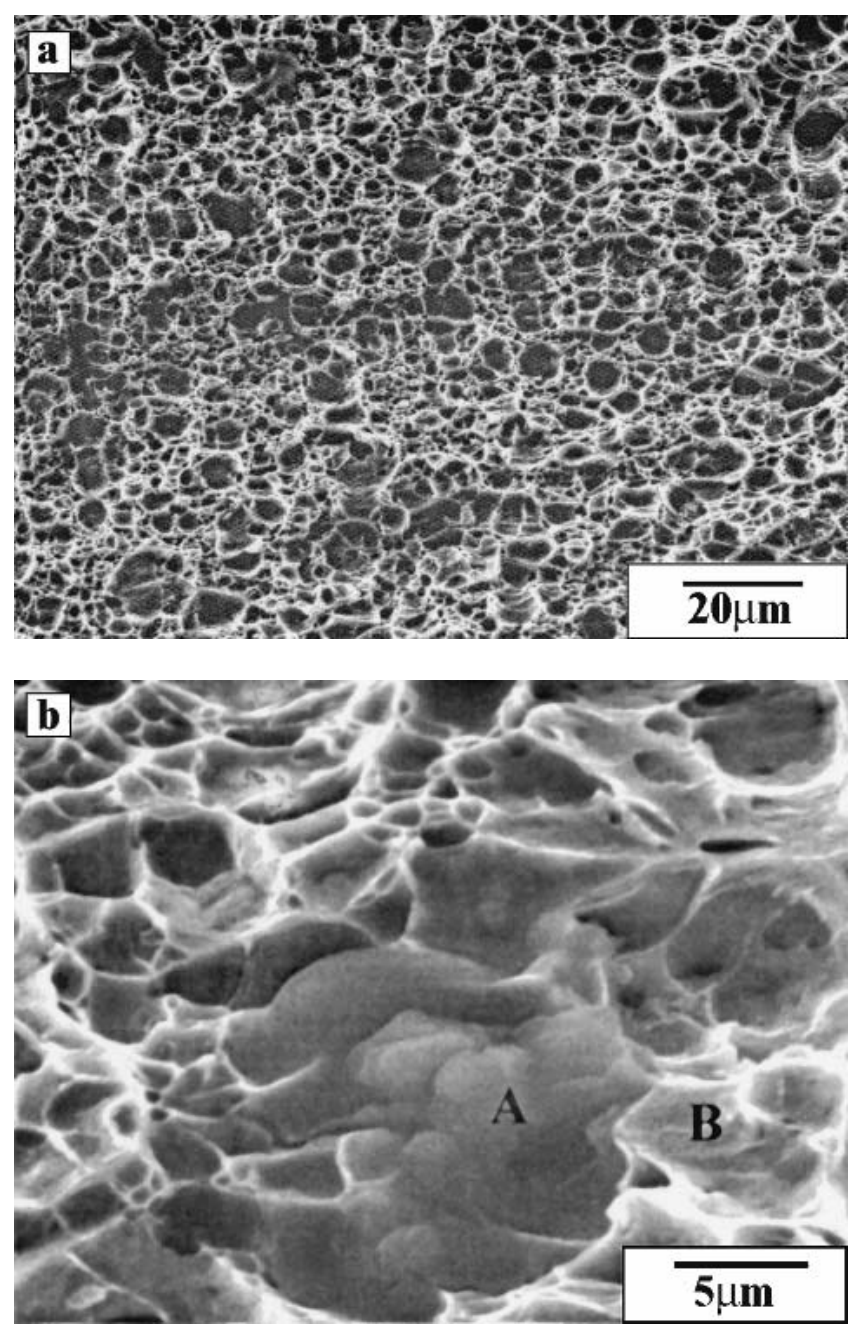

Fig. 10 Scanning electron fractographs of tensile tested in as-formed condition: (a) non-uniform dimples; (b) inclusions in the larger dimples

of crack on the primary inclusion (Fig. 10b). The chemical compositions of the inclusion are Al-rich and Mo-rich as analyzed by EDX (Table 2). The small dimples could only be attributed to the participation of precipitates as sites for crack generation. ${ }^{[13]}$

Aging at $480{ }^{\circ} \mathrm{C}$ for $6 \mathrm{~h}(370-5)$ resulted in a mixture of fine dimple and quasicleavage rupture in the present work (Fig. 11). In general, the features in this case are relatively coarser and exhibit larger deformation. This could be related to possible formation of austenite phase boundaries, to blunt a propagating crack. ${ }^{[14]}$ However, Floreen and Decker reported ${ }^{[15]}$ that plastic deformation can increase the amount of reverted austenite formed before the aging treatment. Ali et al. studied ${ }^{[10]}$ the $18 \mathrm{Ni} 350$ grade maraging steel for aging temperature up to 680 ${ }^{\circ} \mathrm{C}$ and found that the reverted austenite content for a particular aging temperature generally increases with the degree of deformation. The austenite phase appears along the martensite boundaries, but it is difficult to get a representative analysis of these thin layers of austenite by using XRD method. ${ }^{[16]} \mathrm{Be}-$ cause a softer phase is present in a harder matrix, ${ }^{[13]}$ the softer

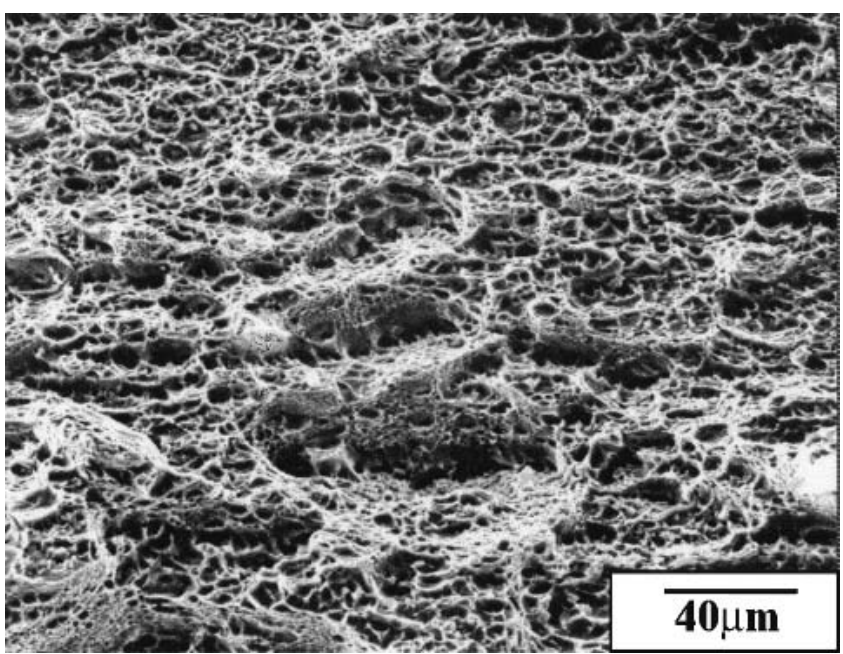

Fig. 11 Scanning electron fractograph of tensile-tested sample in 480 ${ }^{\circ} \mathrm{C} / 6 \mathrm{~h}$

phase will reach the critical strain of fracture at an earlier stage during loading. This would lead to the generation of a series of microcracks in a harder martensitic matrix.

\section{Conclusions}

The following are the main conclusions:

1) After $78.8 \%$ reduction by a flow-formed and a standard aging treatment, the C-250 maraging steel tube has a higher strength and lower elongation than the values of AMS specification $6520 \mathrm{C}$. This is due to the combined effect of work hardening and age hardening. Those values are not suitable to the design requirements.

2) To get appropriate mechanical properties of the flowformed C-250 maraging steel, longer aging times $(>6 \mathrm{~h})$ can be used at an aging temperature of $480{ }^{\circ} \mathrm{C}$.

3) To obtain a better elongation rate for the flow-formed C-250 maraging steel tube, the aging temperature can be increased to $540{ }^{\circ} \mathrm{C}$ for the over-aged condition. In this treatment, the austenite reversion transformation can take place. With an aging treatment of $540{ }^{\circ} \mathrm{C} / 6 \mathrm{~h} / \mathrm{AC}$, a suitable strength value and elongation rate can be obtained. The strengthening phase of the flow-formed C-250 maraging steel was the intermetallic compound of $\mathrm{Fe}_{3} \mathrm{Mo}$.

\section{Acknowledgments}

The authors wish to thank Mechanical Design \& Manufacturing Center and Materials R\&D Division of CSIST for the experimental support.

\section{References}

1. A.M. Hall and C.J. Slunder: "The Metallurgy, Behavior, and Application of the 18-Percent Nickel Maraging Steels," NASA Report SP-5051, 1968.

2. G.E. Linnert: Welding Metallurgy Carbon and Alloy Steel, 3rd ed., AWS, New York, 1967, pp. 517-70. 
3. S. Floreen: AMS Metals Handbook, Vol. 1, 9th ed., pp. 445-52.

4. M. Ahmed, H. Ayub, I. Nasim, F.H. Hashmi, and A.Q. Khan: "Influence of Annealing on Texture and Magnetic Properties of $18 \%$ Nickel $2400 \mathrm{MN}^{-2}$ Grade Maraging Steel," Mater. Sci. Technol., 1995, 11(12), pp. 1281-86.

5. Charles Wick: "Metal Spinning-A Review and Update," Mfg. Eng., 1978, (1), pp. 73-77.

6. W.G. Gates: "Spin-Forming Development," Bindex BDX-613-2709, May 1982.

7. AMS 6512C: "Steel Bars, Forgings, Tubing, and Rings-18Ni-7.8Co4.9Mo-0.40Ti-0.10A1-Consumable Electrode Vacuum Melted, Annealed," Aerospace Material Specification, The Engineering Society for Advancing Mobility Land, Sea, Air, and Space, revised 1 Jul 1991.

8. AMS 6520C: "Steel, Maraging, Sheet, Strip, and Plate-18Ni-7.8Co4.9Mo-0.40Ti-0.10A1-Consumable Electrode Melted, Solution Heat Treated," Aerospace Material Specification, The Engineering Society for Advancing Mobility Land, Sea, Air, and Space, revised Jun 1995.

9. C.H. Cheng: "A Study on Mechanical Properties of C-250 Maraging Steel Weldment and the Influence of Heat Treatment," M.S. Thesis, National Chiao Tung University, Taiwan, R.O.C., 1998.

10. A. Ali, M. Ahmed, F.H. Hashmi, and A.Q. Khan: "Austenite Rever- sion in Cold Formed 18 wt.\% Ni 350 Grade Maraging Steel," Mater. Sci. Technol., 1994, 10(2), pp. 97-101.

11. V.K. Vasudevan, S.J. Kim, and C.M. Wayman: "Precipitation Reactions and Strengthening Behavior in 18 wt.\% Nickel Maraging Steels," Metall. Trans. A, 1990, 21A(10), pp. 2655-68.

12. U.K. Viswanathan, G.K. Dey, and M.K. Asundi: "Precipitation Hardening in 350 Grade Maraging Steel," Metall. Trans. A, 1993, 24A(11), pp. 2429-42.

13. P.P. Sinha, K.T. Tharian, K. Sreekumar, K.V. Nagarajan, and D.S. Sarma: "Effect of Aging on Microstructure and Mechanical Properties of Cobalt Free 18\%Ni (250 Grade) Maraging Steel," Mater. Sci. Technol., 1998, 14(1), pp. 1-9.

14. J. Iqbal, A. Tauqir, F.H. Hashmi, and A.Q. Khan: "Aging Martensite Above As Temperature," Mater. Sci. Technol., 1997, 13(7), pp. 61820.

15. S. Floreen and R.F. Decker: Source Book on Maraging Steels, R.F. Decker, ed., ASM, Metals Park, OH, 1979, pp. 20-32.

16. M. Ahmed, A. Ali, S.K. Hasnain, F.H. Hashmi, and A.Q. Khan: "Magnetic Properties of Maraging Steel in Relation to Deformation and Structural Phase Transformations," Acta Metall. Mater., 1994, 42(3), pp. 631-38. 